\title{
Numerical Simulation of Crack Evolution Mechanism and Subsidence Characteristics Effected by Rock Mass Structure in Block Caving Mining
}

\section{Dongjie Zhang ( $834381852 @ q q . c o m)$}

Inner Mongolia University of Science and Technology https://orcid.org/0000-0001-8284-8758

Jianduo Wang

China Petrochemical Corporation

Shuai Guo

Inner Mongolia University of Science and Technology

Jianli Cao

Northern University

\section{Research Article}

Keywords: Block caving, Numerical simulation, Rock mass structure, Fault

Posted Date: June 7th, 2021

DOl: https://doi.org/10.21203/rs.3.rs-579107/v1

License: (c) (1) This work is licensed under a Creative Commons Attribution 4.0 International License.

Read Full License 


\section{Abstract}

In the block caving mining, the significant rock mass deformation and surface subsidence will be formed with the continuous extraction of ore. However, the internal crack evolution mechanisms in rock mass and associated subsidence characteristics present one of the key issues in rock mining engineering. Although block caving method has been used for many years, current knowledge of the crack evolution mechanisms, the subsidence characteristics under the influence of rock mass structure and subsidence prediction capabilities are limited. Based on the rock mechanics model provided by CEMI, crack evolution mechanisms and subsidence characteristics effected by the rock mass structure in block caving are numerically investigated using RFPA 2D, a numerical code based on FEM. Crack formation, propagation and coalescence in the overlying strata and the stress-balancing arch evolution in the stress field are represented visually during the whole process of extraction. The numerically obtained crack evolution shows that the stress-balancing arch has a significant influence on the fracture development of rock mass, and directly determines the slump form and rate of the rock mass. After understanding of the crack evolution mechanism in rock mass, the characteristics of surface subsidence are analyzed. Numerical experiments emphasize the geometrical configuration of joints and faults about mechanisms of subsidence development, including joints orientation, faults location and inclination, which can provide significantly meaningful guides for investigation of subsidence mechanisms and implementation of remedial measures.

\section{Full-text}

Due to technical limitations, full-text HTML conversion of this manuscript could not be completed. However, the manuscript can be downloaded and accessed as a PDF.

\section{Figures}

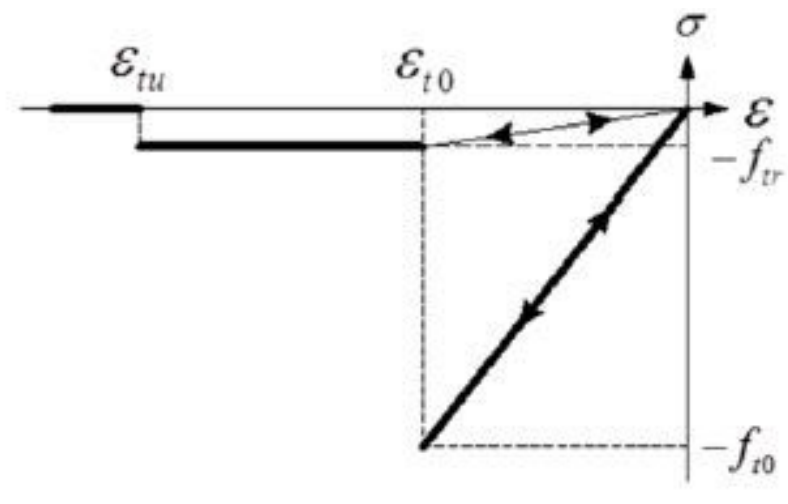

(a)

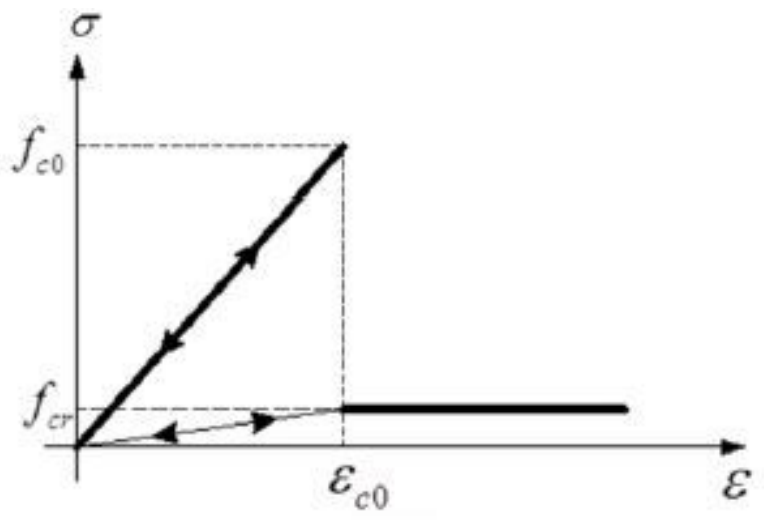

(b)

\section{Figure 1}


Elastic-brittle damage constitutive law of elements subjected to uniaxial stress. (a) The case under uniaxial tensile stress; (b) The case under uniaxial compressive stress

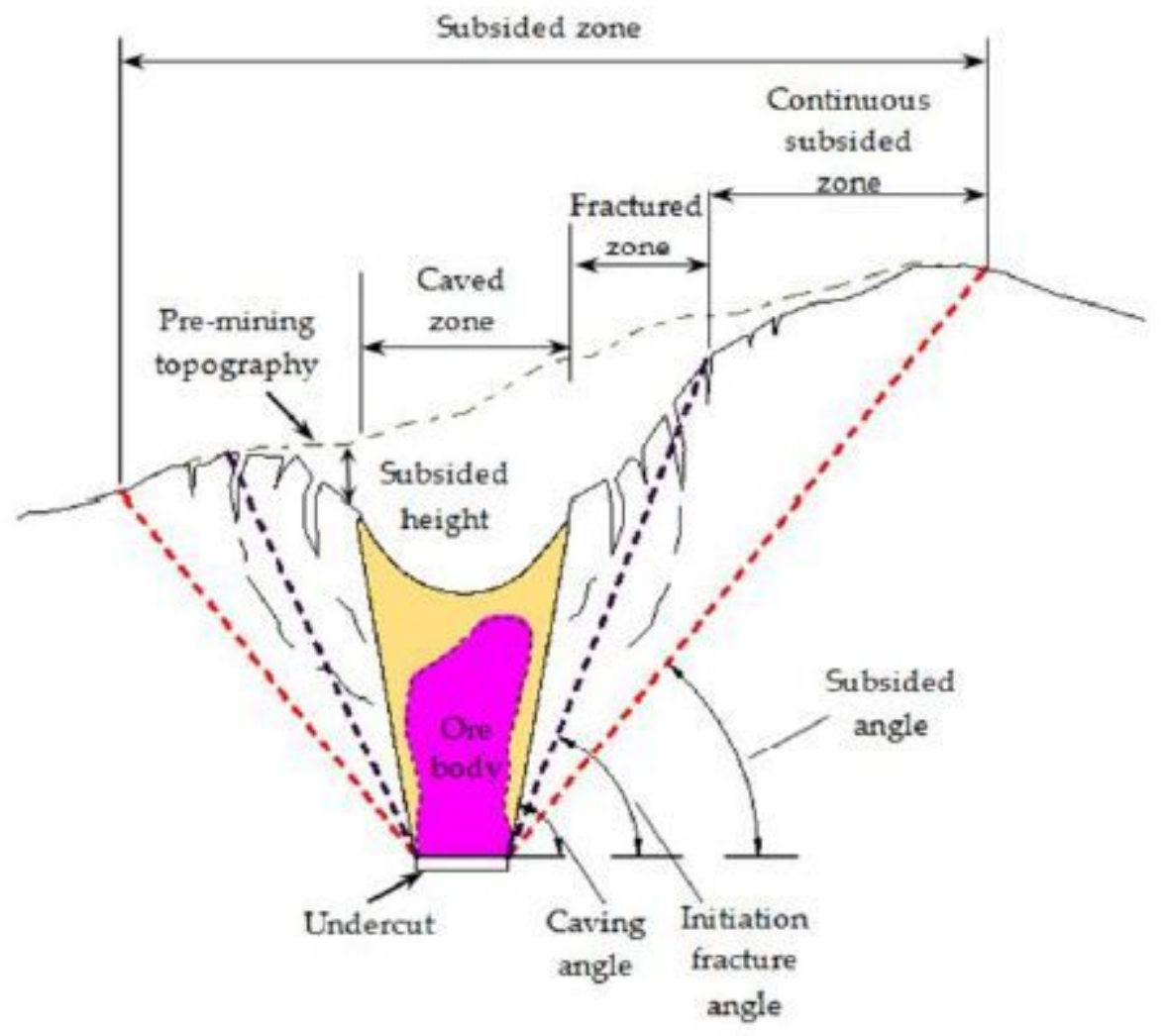

\section{Figure 2}

Conceptual representation of surface subsidence associate with block caving mining, subsidence characterization terminology
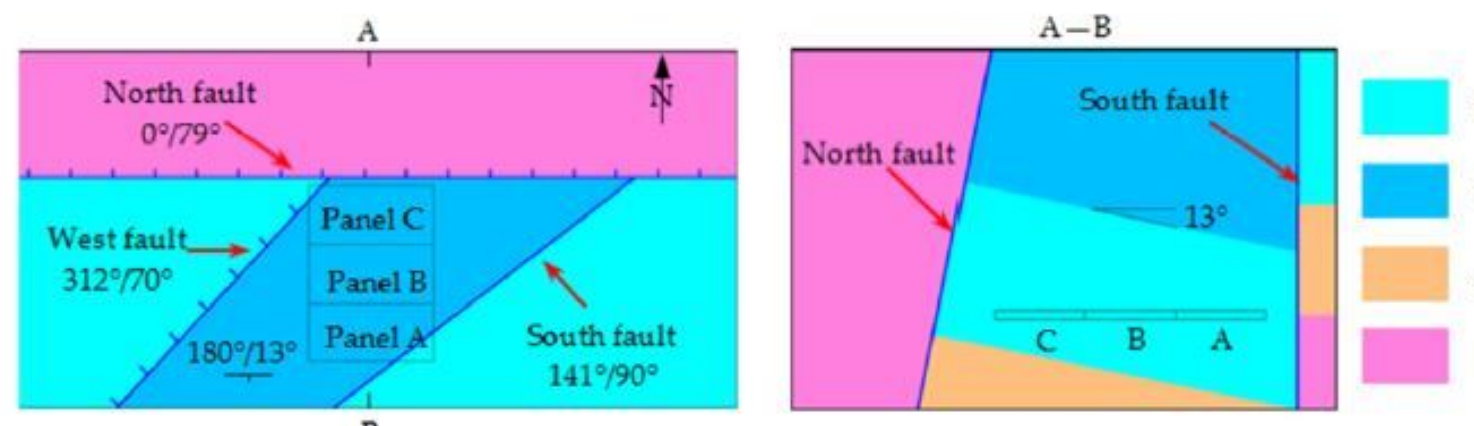

Rhyolite

Quartz-Monzodiorite

Sandstone and Sitlstone

Biotite granodiorite

\section{Figure 3}

Rock mass mechanics model provided by CEMI [20] 


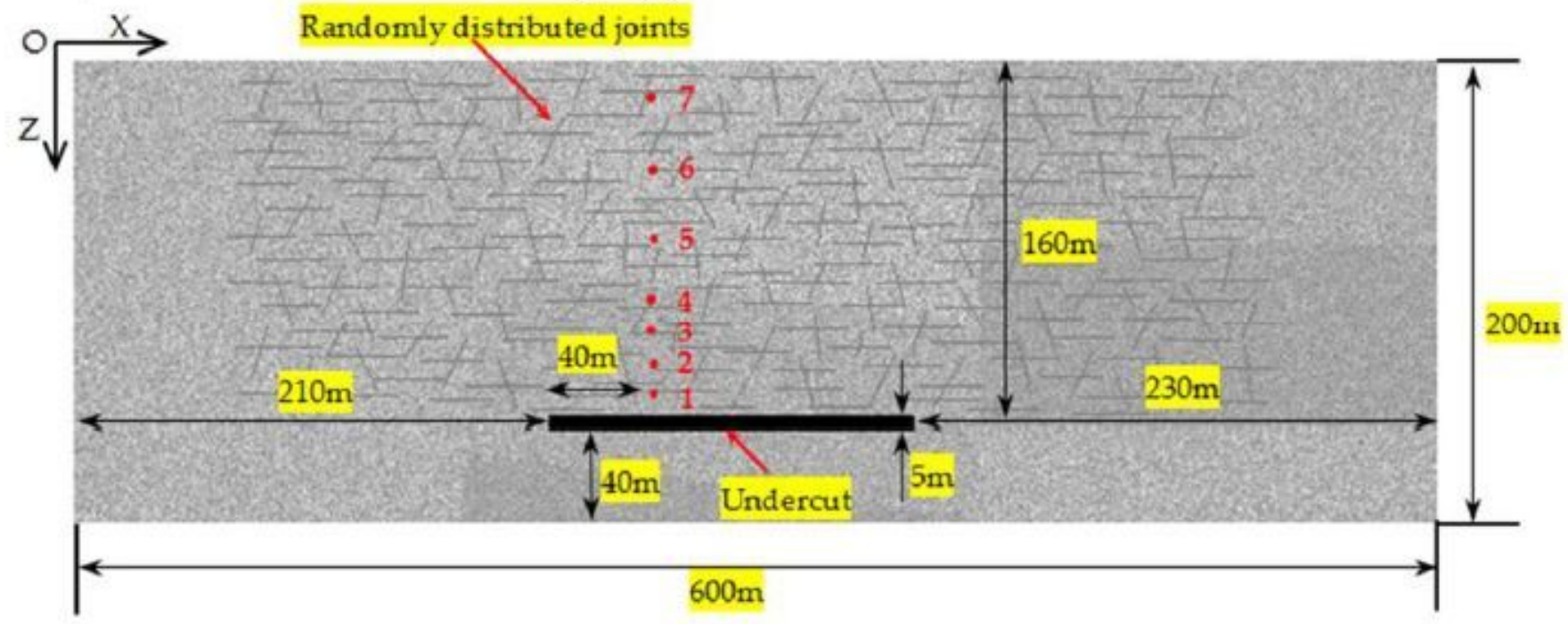

Figure 4

RFPA 2D model (the case with an undercut size of $160 \mathrm{~m}$ ) 

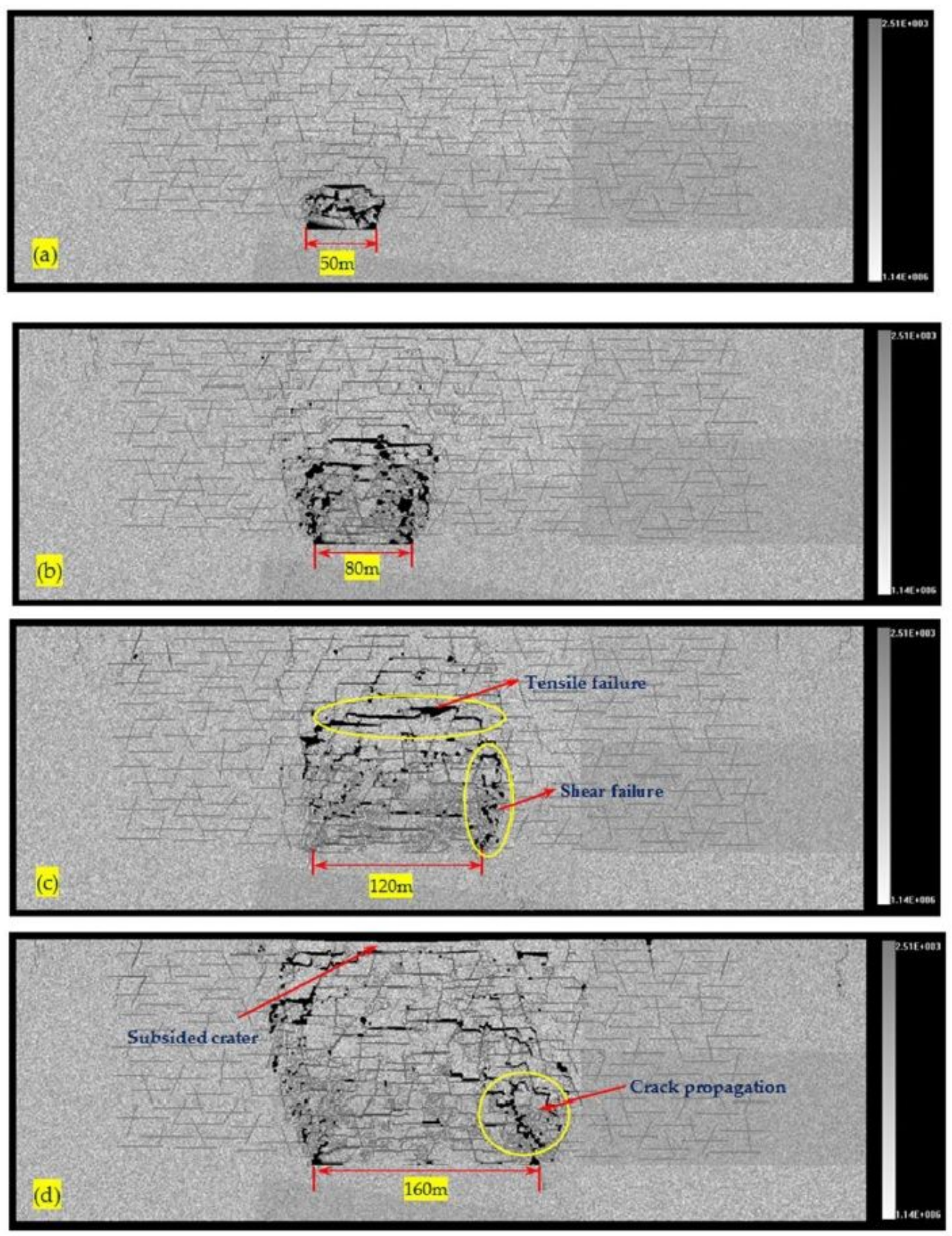

Figure 5

Failure process in different excavation distance 

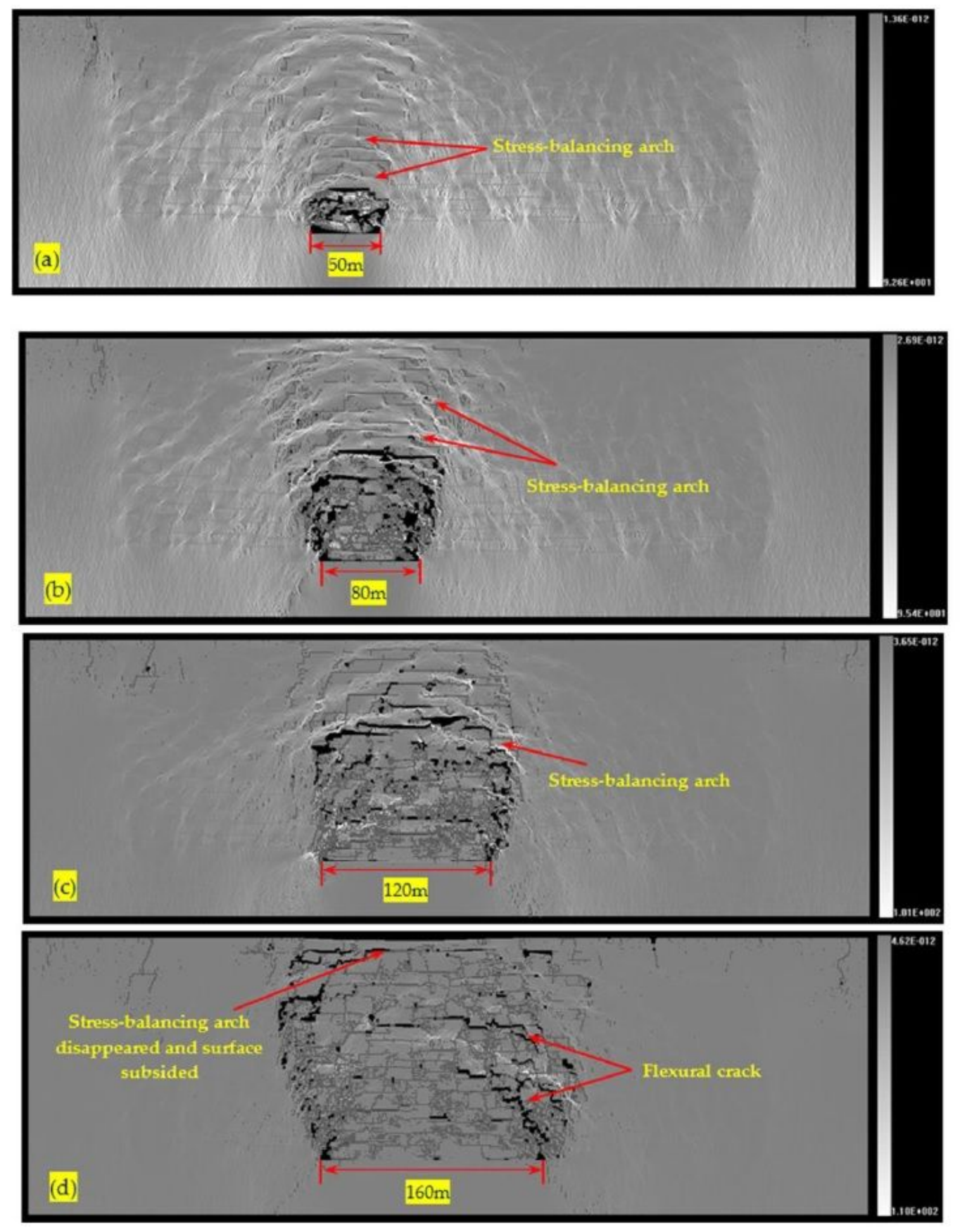

Figure 6

Stress evolution in different undercut size 


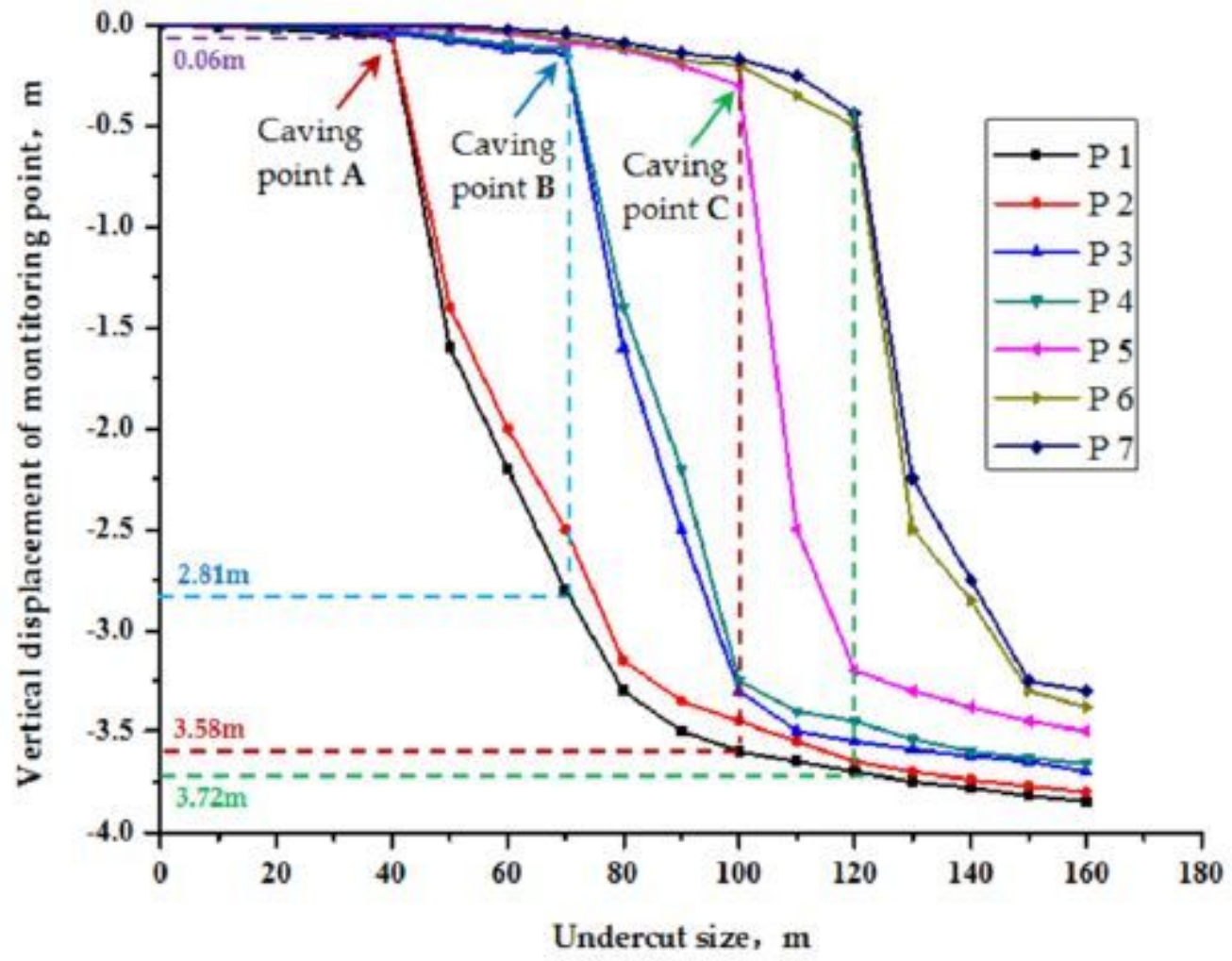

Figure 7

Vertical displacement of different monitoring points in overlying strata 

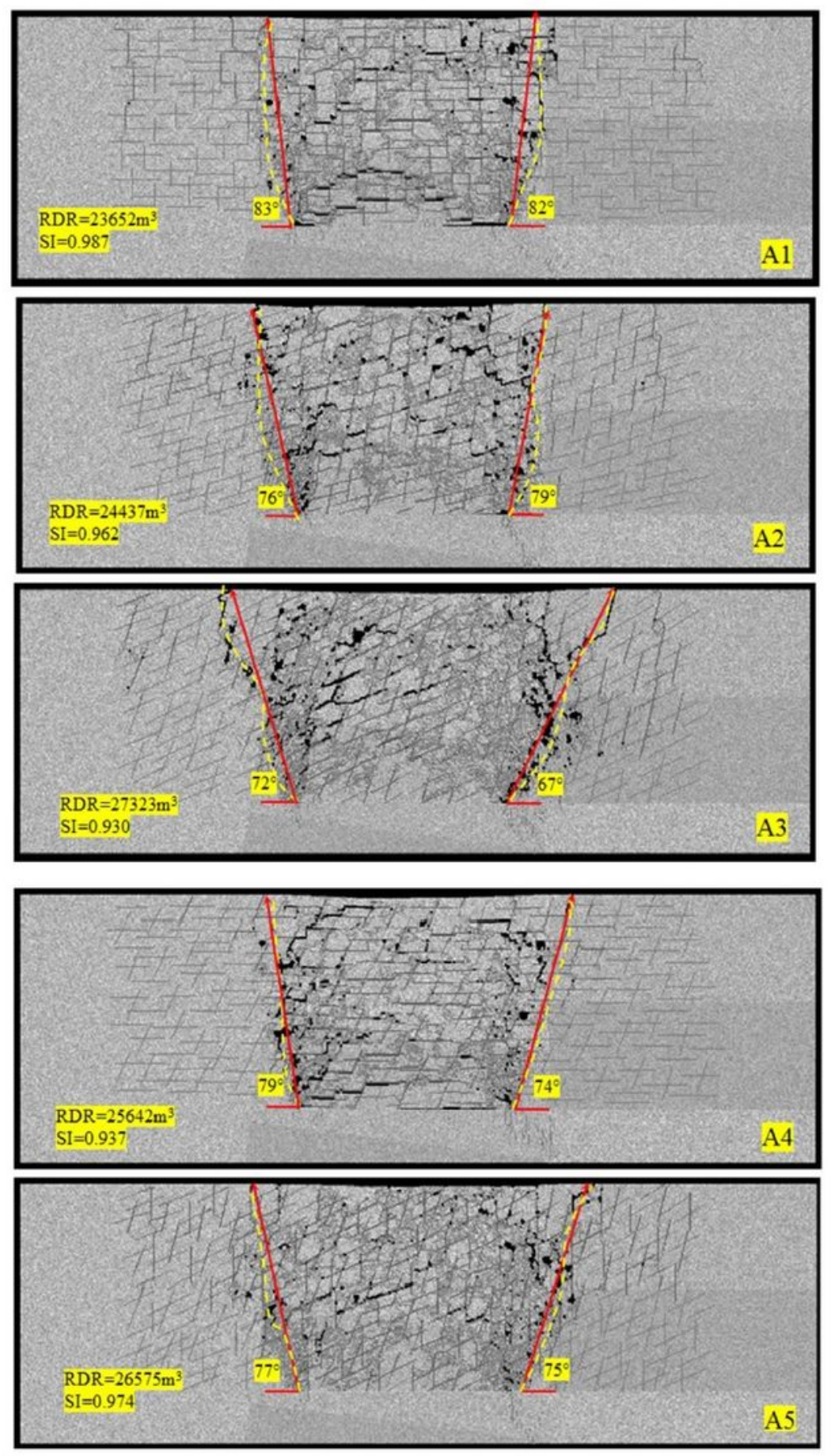

\section{Figure 8}

Subsidence at $160 \mathrm{~m}$ excavation distance for $\mathrm{A} 1, \mathrm{~A} 2, \mathrm{~A} 3, \mathrm{~A} 4$ and $\mathrm{A} 5$ models 


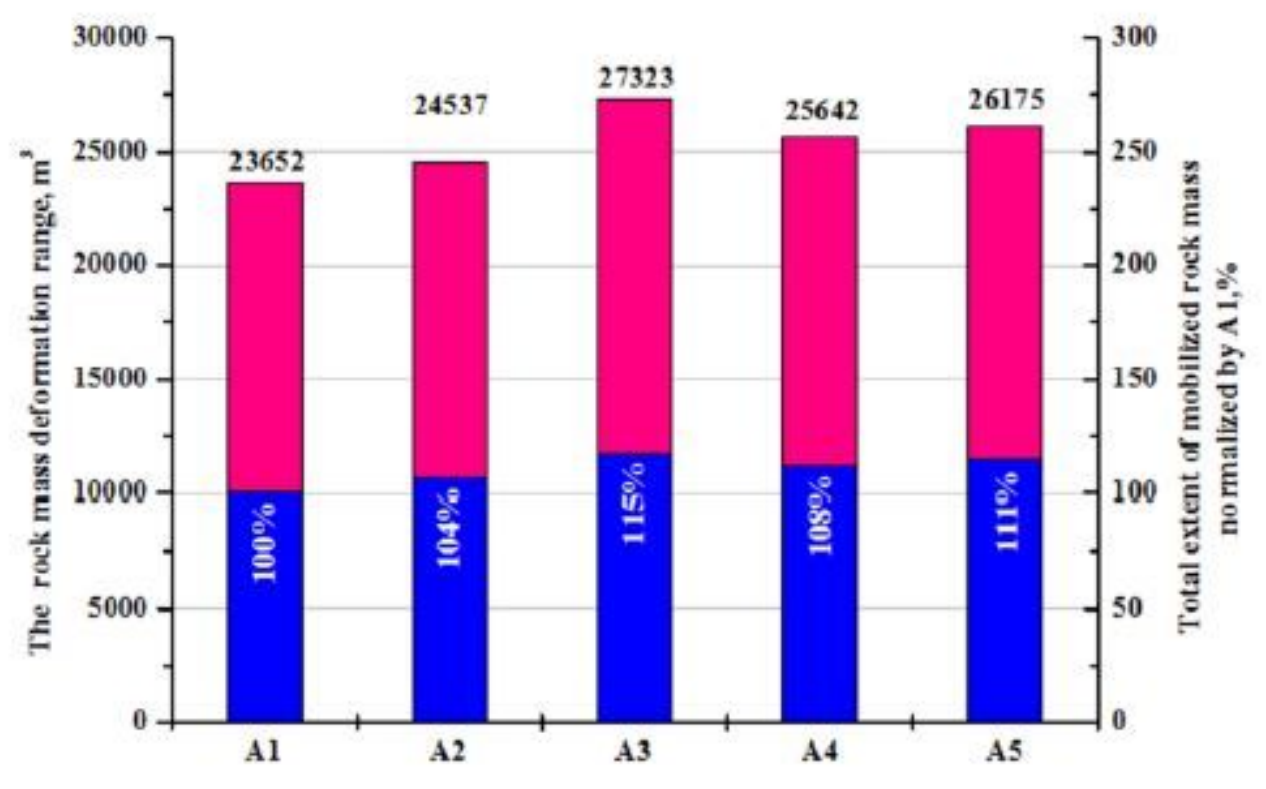

Figure 9

The rock mass deformation range for $\mathrm{A} 1, \mathrm{~A} 2, \mathrm{~A} 3, \mathrm{~A} 4$ and $\mathrm{A} 5$ models

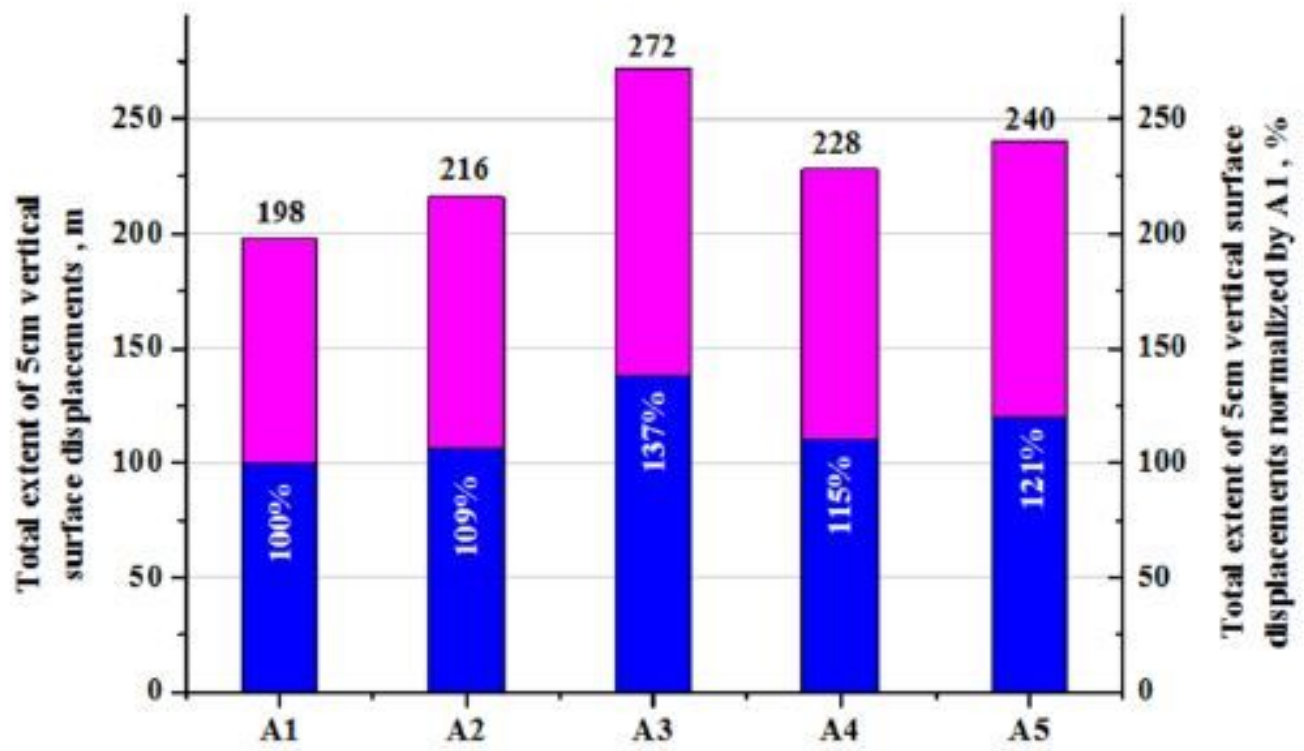

Figure 10

Extent of $5 \mathrm{~cm}$ surface vertical displacements at $160 \mathrm{~m}$ ore extraction, $\mathrm{m}$ 


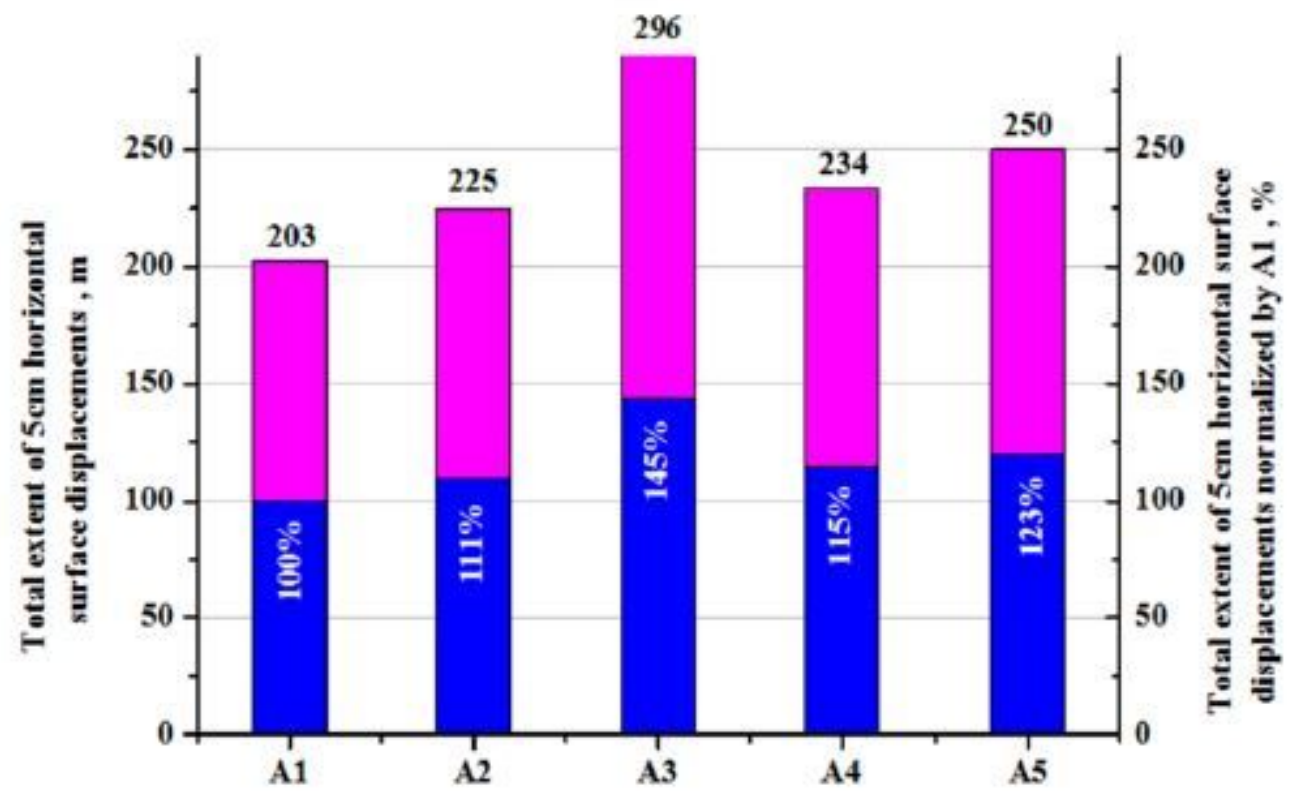

Figure 11

Extent of $5 \mathrm{~cm}$ surface horizontal displacements at $160 \mathrm{~m}$ ore extraction, $\mathrm{m}$
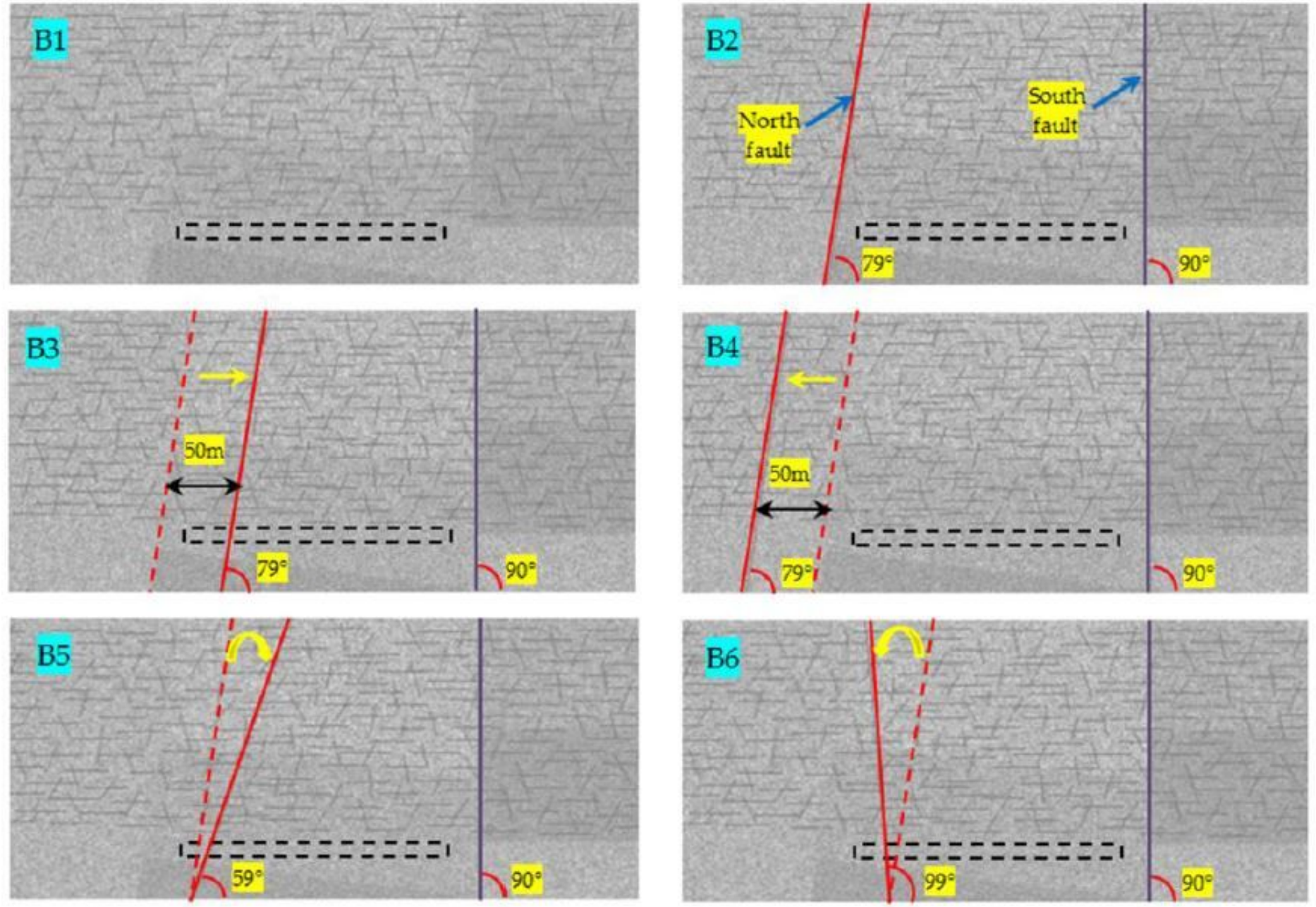
Figure 12

Assumed north fault positions and inclination for B1 B6 models
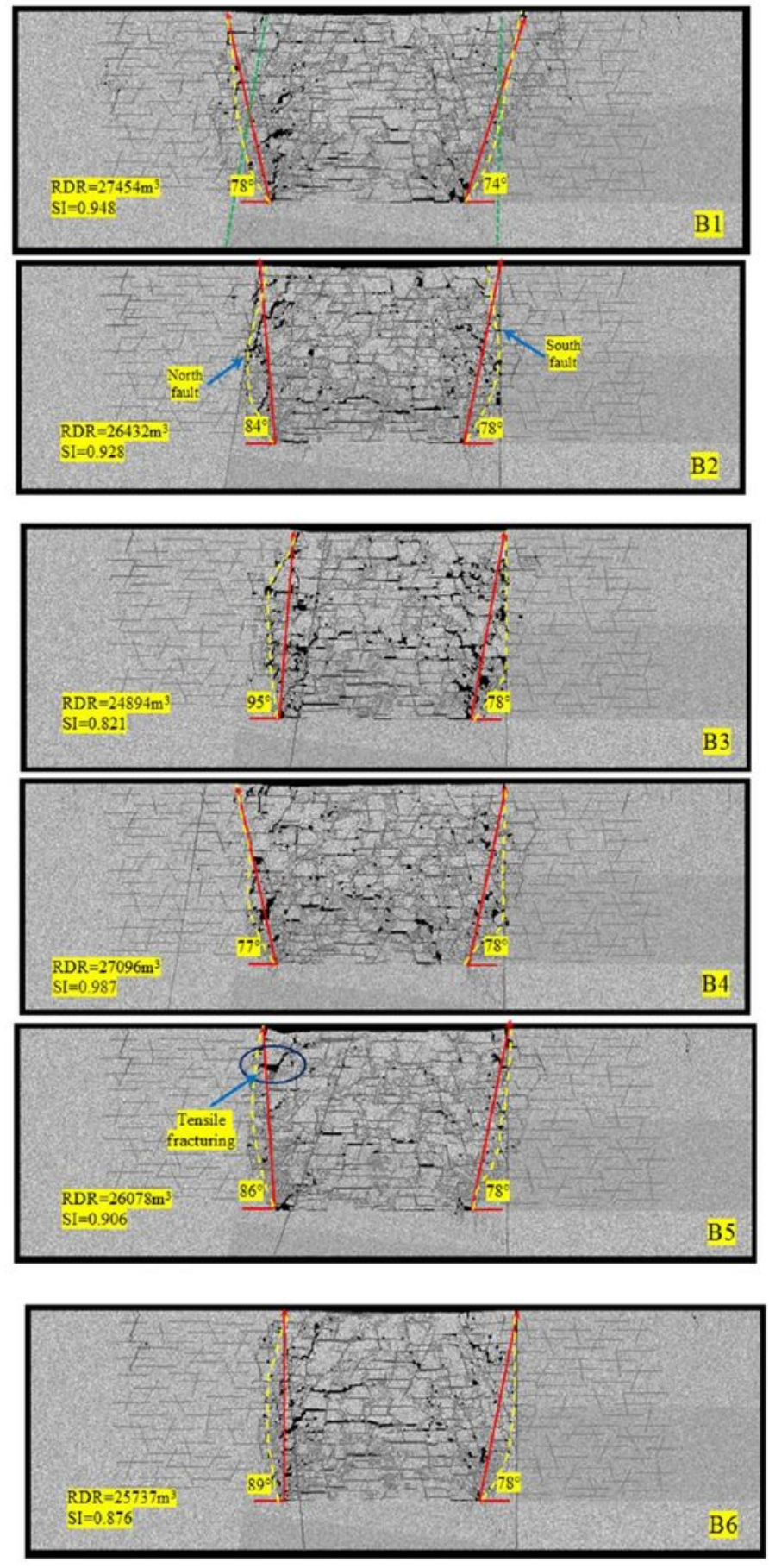

Figure 13

Subsidence at 160m excavation distance for B1, B2, B3, B4, B5and B6 models 


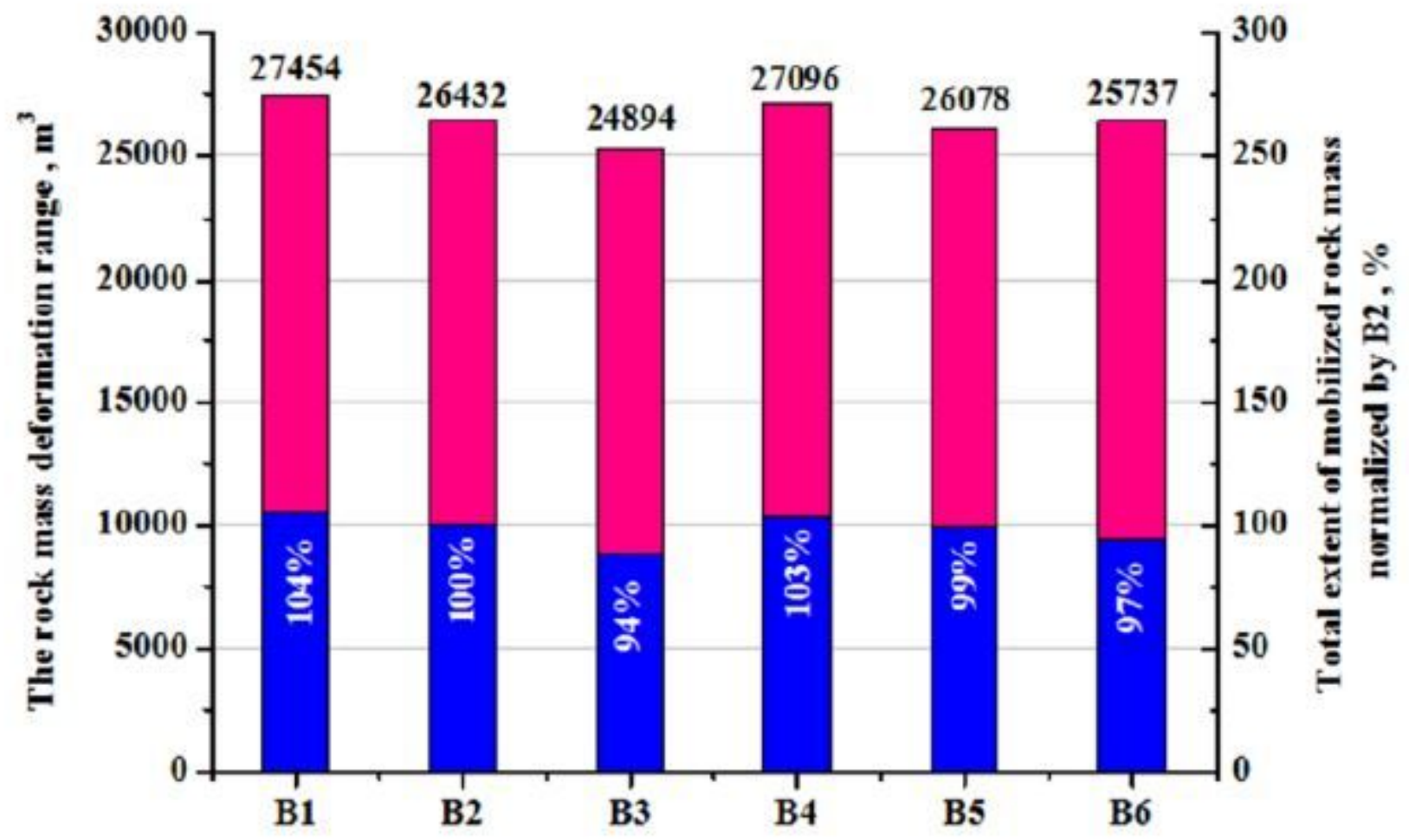

Figure 14

The rock mass deformation range for B1, B2, B3, B4, B5 and B6 models

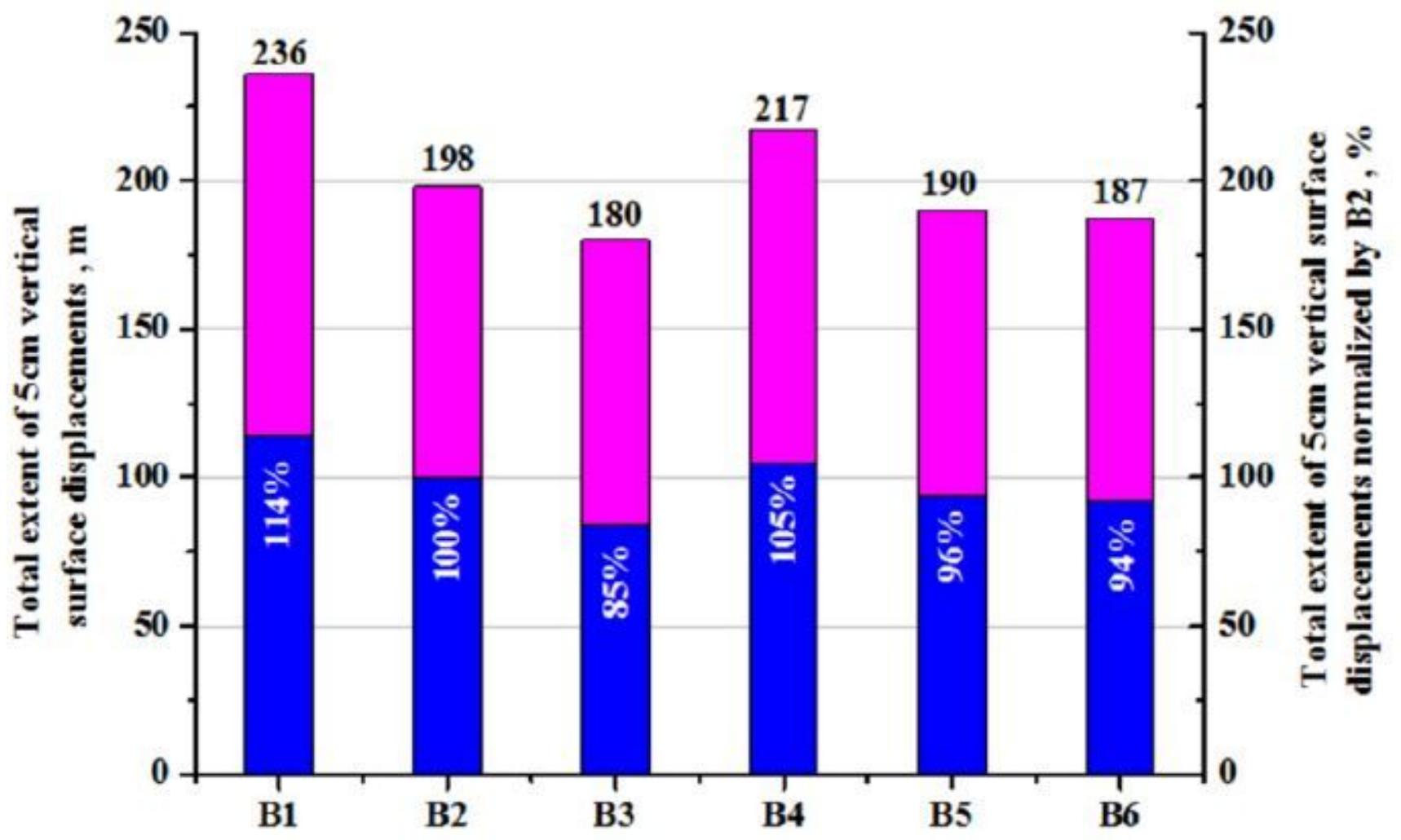

Figure 15 
Extent of $5 \mathrm{~cm}$ surface vertical displacements at $160 \mathrm{~m}$ ore extraction, $\mathrm{m}$

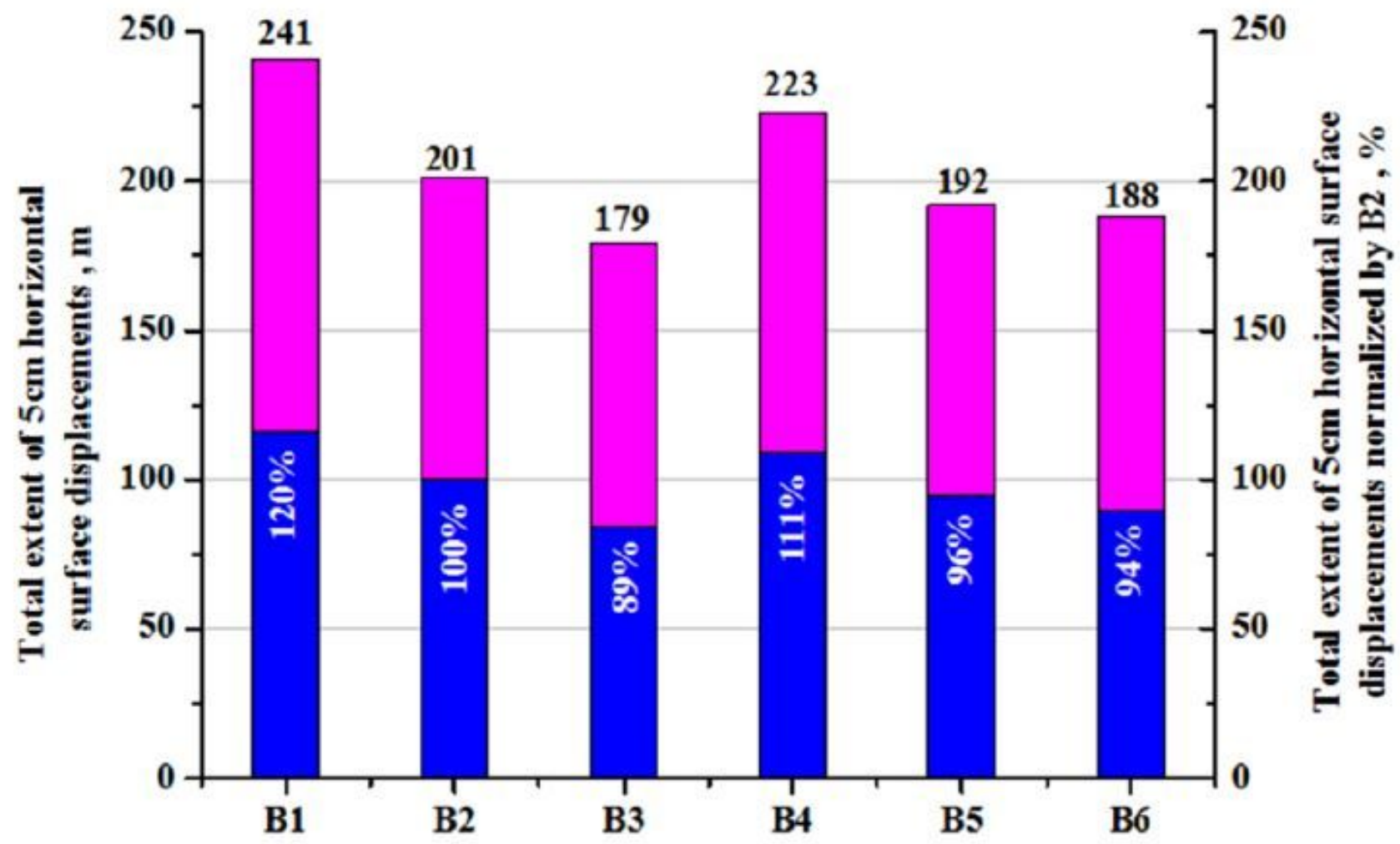

Figure 16

Extent of $5 \mathrm{~cm}$ surface horizontal displacements at $160 \mathrm{~m}$ ore extraction, $\mathrm{m}$ 